\title{
Hope and despair
}

\author{
Vivien Sleight MD LLM
}

J R Soc Med 2004;97:354

'Ah’m tired o' livin', and scared o' dyin' ...'

Jerome Kern

For people who advocate euthanasia today in the UK there is only one kind - voluntary euthanasia. To have the option to choose voluntary euthanasia confers hope - the hope of a good death. Voluntary euthanasia is an intervention specifically at the end of life, as is hospice care, where death is preceded by palliative care that offers all possible relief of suffering without terminating life.

Some view voluntary euthanasia as a form of suicide, but this choice contrasts strongly with acts of suicide arising from despair or futility that may be felt, for instance, by people with severe mental illness. In these cases mental health professionals may to some extent see suicide as a failure of therapy. But for people with terminal illnesses it is the therapy that is futile and death is welcomed simply, wholeheartedly, by the patient.

Much of the conflict arising over voluntary euthanasia is due to semantics. If the different factions became more prepared to listen and to understand each other's terminology, much conflict would be resolved. Mutual understanding and respect for other views, even where irreconcilable differences remain, can only serve to make the debate on voluntary euthanasia more constructive than at present.

Hope is a curiously human characteristic. Hope means that we have the capacity to imagine a future that has not yet happened, as well as learn from our recognition of the past. Much of society's reluctance to be honest about life and death is based on different formalized religious systems, with their varying views about merit in a postulated afterlife. The very best of our attributes include humanity and mercy - these are promoted by most religious systems and supported by moral values. We need to go back to these fundamental values when contemplating the ethical issues surrounding voluntary euthanasia.

Severely mentally ill patients contemplating suicide may have no concept of themselves within the future; this absence of hope is commensurate with total despair. Such despair confirms the presence of an illness needing

Derrydown, Pouchen End Lane, Hemel Hempstead HP1 2SA, UK

E-mail: vsleight@doctors.org.uk therapeutic help from mental health services. By contrast, when there is no possibility of the maintenance of health or restoration of function or a meaningful quality of life, and when death is the inevitable outcome of terminal disease, therapy as such is meaningless. We cannot seriously consider such a situation as humane, merciful, ethical or acceptable when living is so great a burden; and yet, ethically and morally, we cannot allow someone to die.

Two principles underlie the pro-voluntary-euthanasia stance - autonomy and consent. At present the issue remains that, in most countries, doctors who respond to their patients' requests for help to die, when they are no longer physically capable of accomplishing their own death by suicide, are acting illegally. Patients desiring voluntary euthanasia are unhappily aware that they ask their physician to undertake an illegal act, and at present the doctor can officially only decline.

By delineating safeguards so that doctors can assist in a peaceful death at the time of the patient's choosing, the current unlawful practice of voluntary euthanasia which is open to abuse is avoided. Patient refusal to consent to futile treatment must now be honoured in law; but change in the law is needed to allow individuals to decide for themselves what is to be done at the end of life. Legalization of voluntary euthanasia would give hope of control, resurgence of identity and personal dignity.

It should be understood that no doctor is required to undertake any procedure with which he or she does not agree on conscientious grounds. Even were the request legal, it would remain open to all doctors to say that they could not assist the patient specifically to their death; another doctor could and should then be approached.

A hope remains that we may all share - that when each of us reaches the final transition between life and death, the wretchedness of despair is superseded by the hope that one has the legal right to a Good Death, an easy death that is facilitated at the time of one's own choice. The ultimate hope is for voluntary euthanasia to become accepted and legalized so that doctors are secure in their intention to relieve suffering.

Acknowledgment My thanks to Hugh Wynne, PhD, former President of the World Federation of Right-to-Die Societies. 